\title{
Benthic ciliate identification and enumeration: an improved methodology and its application
}

\author{
Stephen Wickham ${ }^{1, *}$, Armin Gieseke ${ }^{2}$, Ulrike-G. Berninger ${ }^{3}$ \\ ${ }^{1}$ Zoological Institute, University of Cologne, Weyertal 119, 50923 Cologne, Germany \\ ${ }^{2}$ Max Planck Institute for Marine Microbiology, Molecular Ecology Group, Celsiusstr. 1, 28359 Bremen, Germany \\ ${ }^{3}$ Institut für Meereskunde der Christian-Albrechts-Universität Kiel, Abt. Meeresbotanik, Düsternbrooker Weg 20, \\ 24105 Kiel, Germany
}

\begin{abstract}
The study of the ecological role played by benthic ciliates is hampered by the lack of a methodology to accurately enumerate benthic ciliates with good taxonomic resolution. As a result, a technique was developed that combined 2 previously published methods developed to identify and count pelagic ciliates and benthic flagellates, respectively. The new method utilizes centrifugation in a non-linear density gradient to separate ciliates from sediment, and the QPS (quantitative protargol stain) silver-staining technique to stain the cilia and nuclei of ciliates which, after centrifugation, are concentrated on cellulose nitrate filters. The wide applicability of the method was shown by utilizing it to count and identify ciliates in cores taken from intertidal sediment and sampled on a $2 \mathrm{~mm}$ depth interval. The intertidal cores had a total of 41 species or morphotypes present, but no more than 21 species or morphotypes in any single $2 \mathrm{~mm}$ layer. Total ciliate abundance was as high as $2500 \mathrm{cells} \mathrm{ml}^{-1}$, with the upper layers having higher abundance than deeper layers. There was no obvious pattern with depth either for the number of species found in any one layer, or for ciliate diversity. The method was further utilized in an experiment that explored the interactions between benthic ciliates and the ostracod Cyrideis trosa. Ostracods reduced the final abundance of ciliates, but this effect was confined to the upper $5 \mathrm{~mm}$ of sediment. Two-thirds of the ostracods were found in the 5-10 $\mathrm{mm}$ layer at the end of the experiment, but while there was an effect on ciliate diversity in this layer, there was no effect on total ciliate abundance. We conclude that the method is suitable for studying both the natural distribution and diversity of benthic ciliates and their response to experimental manipulations.
\end{abstract}

KEY WORDS: Benthic ciliate distribution · Benthic ciliate enumeration · Benthic ciliate identification · Ostracod

\section{INTRODUCTION}

The diversity and functional role of ciliates has been a recent topic of discussion in the literature (Finlay et al. 1996, Fenchel et al. 1997, Finlay \& Esteban 1998). While the functional role and abundance of pelagic ciliates is reasonably well understood, research on benthic ciliates is not as advanced. Work with natural communities of benthic ciliates has shown distribution patterns in response to abiotic and biotic factors (Fenchel 1969, Epstein \& Gallagher 1992, Berninger \& Epstein 1995, Epstein 1997, Lucchesi \& Santangelo

*E-mail: steve.wickham@uni-koeln.de
1997). Nevertheless, the trophic role of benthic ciliates is not nearly as well understood as that of pelagic ciliates. While simply knowing the number of species in an area of a given size has yielded a wealth of information central to community ecology (e.g. MacArthur \& Wilson 1967, Tilman \& Downing 1994), many other questions, such as those about species distribution patterns, ecosystem stability, and biotic diversity, require not only species number, but the abundance or biomass of individual species (e.g. MacArthur 1957, Hairston 1969, Brown 1984, Tilman 1996). Clearly, hypotheses about benthic protist community associations or about predator-prey or competitive trophic relationships require both the number of species or trophic groups, and the abundance of individuals of the 
species or group. Ecologically important differences between morphospecies in the genus Euplotes have already been demonstrated (Dini \& Nyberg 1999), emphasizing the importance of combining good taxonomic resolution with accurate enumeration of benthic ciliates. It has been hypothesized that benthic ciliates consume only a minor amount of benthic bacterial production (Kemp 1988, 1990, Epstein \& Shiaris 1992), but without satisfactory methods for enumerating benthic ciliates and differentiating between species the hypothesis cannot be adequately tested.

A major reason for the lack of understanding of benthic protists is the methodological difficulties encountered when working with benthic organisms. Gradients of light, oxygen and redox potential are orders of magnitude steeper in sediment than in the overlying water (Jørgensen \& Revsbech 1985, Kühl et al. 1994, Berninger \& Huettel 1997), requiring sampling on a very fine spatial scale. What is normally an even greater problem is the difficulty in separating cells from sediment particles. Uhlig's (1964) method utilizes ice to create a temperature and osmotic gradient which drives ciliates from the sediment, but this is not quantitative and may select against entire ciliate groups (Uhlig 1964, Alongi 1986). Live counting either only identifies and enumerates larger ciliates (Goulder 1971), or it uses replicate counts of highly dilute samples to separate ciliates from sediment (Finlay et al. 1979, Gasol 1993). As a result, live counting is only appropriate when there is only a small number of samples to count, and the samples can be counted immediately. This precludes using live counting in experimental work, for which multiple samples are generated simultaneously. Alongi (1986) developed a method using centrifugation in the silica gels Percoll and Sorbitol to separate protists from sediment. However, in Alongi's method, the distance travelled by the protists was a function of the speed and duration of centrifugation, and the protists were subsequently counted in a petri dish under a dissecting microscope (Alongi 1986). Starink et al. (1994) improved this technique by first creating a non-linear density gradient in the Percoll, by centrifuging a Percoll-water solution at high speed prior to sample addition and a second centrifugation step. This creates a region at the bottom of the centrifuge tube which is too dense for protists (in this case heterotrophic nanoflagellates) to enter into, but not too dense for sediment particles. Thus, the sediment forms a pellet at the bottom of the centrifuge tube, while the flagellates remain suspended in the Percoll-water solution above (Starink et al. 1994). This technique was later applied by Epstein (1995) to separate ciliates from sediment. However, Epstein stained his cells with 2 epifluorescent dyes. This has the disadvantages that the cells can only be observed for a short time before the dye fades, that the ciliature is not well stained, restricting the degree of taxonomic resolution, that there is sometimes background fluorescence from remaining detritus particles, and that no permanent record of the sample remained.

In this paper we outline a method that allows benthic ciliates to be enumerated with good taxonomic resolution, and that creates a permanent record of the sample. The methodology is a combination of the non-linear density gradient method of Starink et al. (1994) and the staining procedure of Montagnes \& Lynn (1987). We then applied the technique in both field and laboratory studies. The field work involved enumerating the ciliates in intertidal sediment samples at a fine $(2 \mathrm{~mm})$ spatial resolution, while the experiment in the laboratory tested the hypothesis that meiofauna (in this case the ostracod Cyrideis trosa) could have a measurable impact on benthic ciliates. In this way, we hoped to demonstrate the advantages of the technique and its applicability to ecological questions regarding benthic ciliates.

\section{MATERIAL AND METHODS}

Ciliate enumeration. The methodology developed was a combination of the non-linear density gradient method developed by Starink et al. (1994) for the enumeration of flagellates (and by Epstein [1995] for the enumeration of ciliates) and the Quantitative Protargol Stain (QPS) developed by Montagnes \& Lynn (1987), as modified by Skibbe (1994). Both Starink et al. (1994) and Epstein (1995) used Percoll to establish density gradients with a region that was too dense for protists to pass through, but not so dense that sediment would be retained. Percoll (Amersham Pharmacia Biotech, Little Chalfont, UK) consists of colloidal silica particles coated with Polyvinylpyrrolidone (molecular diameter of $20 \mathrm{~nm}$ ). Similar to Epstein (1995), we used a 1:1 solution of Percoll and twice-concentrated sample water as the medium in which the density gradient was established. The twice-concentrated sample water, from the same sampling location as where the sediment cores were taken, was GF/F filtered and concentrated by the evaporation of warmed water. The water was concentrated in order to retain the original osmolarity of the sample water in the 1:1 Percoll-water solution. We used 2 different centrifuges and 2 different sets of centrifuge speeds and durations, but obtained essentially identical density gradient profiles (Fig. 1). For the ostracod experiment, we used $8 \mathrm{ml}$ of the Percoll-water solution, centrifuged in $10 \mathrm{ml}$ Naglene polycarbonate Oak Ridge centrifuge tubes at $20000 \times g$ for $1 \mathrm{~h}$ in a fixed-arm rotor in a Heraeus Sepatech Megafuge 1.0R centrifuge at $18^{\circ} \mathrm{C}$. The protocol for the Wattenmeer 
sediment profiles also used $8 \mathrm{ml}$ of the Percoll-water solution, but the solution was centrifuged for $25 \mathrm{~min}$ at $38600 \times g$ in Beckmann Polyallomer centrifuge tubes $(14 \times 89 \mathrm{~mm})$ on a Beckman L70 (type Optima L) ultracentrifuge by use of a swinging bucket rotor (Beckman, type SW $41 \mathrm{Ti}$ ) at $4^{\circ} \mathrm{C}$. The density gradients were checked by removing from the centrifuge tubes $50 \mu \mathrm{l}$ sub-samples at $5 \mathrm{~mm}$ intervals and weighing them. In order to ensure that the density gradients were replicable and stable, density gradients were established on different dates and then measured either 0, 1 and $17 \mathrm{~d}$ (Heraeus centrifuge), or 0, 5 and $20 \mathrm{~d}$ (Beckman centrifuge) after the establishment of the gradient.

Ciliates were sampled using plexiglass mini-cores inserted into the sediment (ostracod experiment: $150 \times$ $24 \mathrm{~mm}$ cores inserted 70 to $80 \mathrm{~mm}$ into the sediment; Wattenmeer sediment profiles: $200 \times 36 \mathrm{~mm}$ cores inserted $150 \mathrm{~mm}$ ). Stoppers with a hole bored through them and rubber tubing attached were placed in the tops of the cores before they were inserted into the sediment, and as the cores were inserted a partial vacuum was created to prevent compaction of the sediment. The mini-cores were then extracted, and stoppers were placed in the bottom of the cores. For the ostracod experiment, the cores were extruded and sliced in $0-5 \mathrm{~mm}$ and 5-10 $\mathrm{mm}$ sections, giving a sample volume of $2.33 \mathrm{ml}$. The Wattenmeer sediments were extruded and cut into $2 \mathrm{~mm}$ sections to a depth of $20 \mathrm{~mm}$ (sample volume, $2.0 \mathrm{ml}$ ). The samples were fixed in $1 \%$ (ostracod experiment) or $1.6 \%$ (Wattenmeer) final concentration glutaraldehyde solution (diluted with filtered water from the sampling location) to give a final volume of $10 \mathrm{ml}$ glutaraldehyde-fixed sample. The samples were then stored in $50 \mathrm{ml}$ plastic centrifuge tubes at $4^{\circ} \mathrm{C}$.

In the ostracod experiment, the samples were washed prior to centrifugation in a manner similar to Epstein (1995) in order to achieve an initial separation of protists from the denser sediment particles. The samples were shaken and then allowed to stand for approximately $5 \mathrm{~s}$. A $5 \mathrm{ml}$ sample (50\% of the sample volume) was removed with an Eppendorf pipettor with the opening enlarged to prevent sediment particles from blocking the tip. The remaining $5 \mathrm{ml}$ sample was then increased to $10 \mathrm{ml}$ again by adding $5 \mathrm{ml}$ of a $1 \%$ glutaraldehyde solution. This $10 \mathrm{ml}$ sample was also shaken, and another $5 \mathrm{ml}$ was removed. The procedure was repeated for a total of 5 times, resulting in $25 \mathrm{ml}$ of washed sample. Assuming that protists were randomly distributed in the solution immediately after shaking, 5 rinses removed $97 \%$ of the protists present in the initial sample (if $50 \%$ of the protists present remain behind after every rinse, then after 5 rinses there will be $0.5^{5} \times$ $100=3.1 \%$ of the original sample remaining). The remaining sediment was checked by examining diluted $1 \mathrm{ml}$ samples in a Sedgewick-Rafter counting chamber. With the exception of ostracods and snails, no meiofauna or protists were found. The Wattenmeer sediment was too fine to allow a substantial improvement of ciliate separation by washing (median grain size, $86 \mu \mathrm{m})$.

After the sediment samples had been washed, $1.5 \mathrm{ml}$ (ostracod experiment) or $1.0 \mathrm{ml}$ (Wattenmeer sediment) of the sample was carefully placed on top of the density gradient in the centrifuge tubes. These were then spun at either $5000 \times g$ (Heraeus centrifuge) or $4300 \times g$ (Beckman centrifuge) for $15 \mathrm{~min}$ in a swingarm rotor. The upper approximately $5 \mathrm{~cm}$ of the sample, to just above the sediment pellet, was then removed using a Pasteur pipette. This suspension was filtered onto a $25 \mathrm{~mm}, 1.2 \mu \mathrm{m}$ pore-size cellulose nitrate filter with a black grid pattern. The grid could theoretically be used when counting sub-samples on the filter, but in practice was most useful in determining which side of the filter was the upper side during the staining procedure. Preliminary tests did not reveal any advantage in using 3.0 or $5.0 \mu \mathrm{m}$ pore-size filters, and as a result, the less-expensive $1.2 \mu \mathrm{m}$ filters were routinely used. The remaining filter pellet was checked in preliminary tests by diluting the pellet and examining it using a Sedgewick-Rafter counting chamber and at $100 \times$ magnification.

Glutaraldehyde was used as a fixative because Percoll forms a gel too dense to pass through a filter at a $\mathrm{pH}$ less than 4.5. This theoretically precludes the use of acidic fixatives such as Bouin's or acid Lugol's. However, it was found that with $5 \%$ Bouin's as a fixative, the gel requires at least $30 \mathrm{~min}$ to become established, leaving enough time to filter the samples after they have been centrifuged. Samples that stood for $15 \mathrm{~min}$ after centrifugation could still be filtered, but samples left standing for $30 \mathrm{~min}$ post-centrifugation were not usable. Nevertheless, glutaraldehyde was chosen as a fixative because the time frame using Bouin's was too short to process more than 2 samples.

Once the samples had been concentrated on the filters, they were stained using the Skibbe (1994) version of the Montagnes \& Lynn (1987) QPS method. Protargol is a silver proteinate stain, which stains cilia as well as internal structures such as microtubuli, extrusomes and nuclei (Lynn 1992). After the ciliates were collected on a cellulose nitrate filter and embedded in agar, they were bleached using potassium permanganate, stained first with Protargol and then briefly with gold chloride. The stain was subsequently fixed with sodium thiosulfate, and the cells were dehydrated with an alcohol series. Finally, the filters were mounted on slides with a permanent mounting medium such as Canada Balsam (Montagnes \& Lynn 
1987, Skibbe 1994). Except for lengthening the duration of the $\mathrm{KMnO}_{4}$ step (see 'Results'), and adding of a $90 \%$ isopropyl alcohol dehydration step, Skibbe's protocol was followed. Filters were counted in their entirety using light microscopy at a magnification of $200 x_{\text {; }}$ magnifications of $400 \times$ and $630 \times$ were used for identifications.

Wattenmeer sediment profiles. The sediment samples were obtained from the Lower Saxony Wattenmeer National Park, on the North Sea coast of Germany, north of the Weser estuary $\left(53^{\circ} 44^{\prime} 00^{\prime \prime} \mathrm{N}\right.$, $8^{\circ} 30^{\prime} 20^{\prime \prime} \mathrm{E}$ ). The samples were taken in October 1996 at low tide, approximately $250 \mathrm{~m}$ seaward of the high tide mark. The sediment in this area is a fine sand (87\% of the particles in Wentworth class 4 , or 0.125 to $0.0625 \mathrm{~mm}$ diameter) with an average water content of $31 \%$ (salinity, 36 PSU) and an organic content of $2 \%$ (dry weight). Two cores were taken in shallow tidal pools with 10 to $30 \mathrm{~mm}$ of overlying water by inserting $36 \times 200 \mathrm{~mm}$ plastic cores approximately $150 \mathrm{~mm}$ into the sediment. The cores were stoppered at the top, extracted, and then stoppered at the bottom. The samples were then placed in a water-filled pail until processing at the sampling site to maintain a constant temperature. The cores were extruded in $2 \mathrm{~mm}$ sections, and the sediment fixed in glutaraldehyde with an end concentration of $1.6 \%$. A total of 10 samples were taken per core, to a depth of $20 \mathrm{~mm}$. A further 2 cores were taken and extruded as above, but not fixed, in order to make live observations to aid the identification of the ciliates. Ciliates were identified using mainly Carey (1992), Small \& Lynn (1985) and Kahl (1930-1935) as guides. Ciliate biodiversity was calculated using the Shannon-Wiener diversity index $\left(H^{\prime}\right)$. This is calculated as

$$
H^{\prime}=-\sum p_{i} \times \ln \left(p_{i}\right)
$$

where $p_{i}$ is the proportion of the total ciliate abundance made up by species $i$. The maximum diversity occurs when each species has the same proportion of the total abundance, and is equal to the natural logarithm of the species richness (the total number of species).

Ostracod experiment. Sediment samples were obtained from a standard sampling station in the Rassower Strom, a brackish water inlet (salinity, 8 to $12 \mathrm{PSU})$ on the Baltic island of Rügen $\left(54^{\circ} 34^{\prime} \mathrm{N}\right.$, $\left.13^{\circ} 10^{\prime} \mathrm{E}\right)$. Water depth at the sampling station was approximately $3.5 \mathrm{~m}$. Sediment cores were taken on 8 July 1996 with a multi-corer, using nine $8.5 \times 60 \mathrm{~cm}$ plastic cores. These were brought directly to shore, and 3 cores were chosen at random for initial samples. The cores were sampled by inserting into each a $23 \times 150 \mathrm{~mm}$ plastic mini-core and extracting 2 samples from $0-5$ and 5-10 $\mathrm{mm}$ sediment depths as described above. The sediment was black from $\mathrm{FeS}_{2}$ at approximately $5 \mathrm{~mm}$ depth, indicating that the 0-5 mm depth sample included both oxic and anoxic zones, while the 5-10 $\mathrm{mm}$ sample was restricted to the anoxic layer. The samples were then fixed in $1 \%$ glutaraldehyde fixative (final concentration) and later stained as described above. In order to obtain an accurate count of ostracods in the sample, the portion of the sample remaining after the washes described above was examined with a dissecting microscope, and the ostracods were counted and measured with an ocular micrometer. The remaining 6 cores were prepared for the experiment as follows: In each core, 2 of the $23 \times 150 \mathrm{~mm}$ mini-cores were inserted 70 to $80 \mathrm{~mm}$ into the sediment, leaving approximately $20 \mathrm{~mm}$ of the tubes above the overlying water, in order to prevent the potential ciliate predator Neomysis integer from entering the tubes. One mini-core was used for the experimental manipulation, and the other served as a control. We inoculated each of the experimental mini-cores with 200 ostracods of the species Cyrideis trosa, giving an initial density of 43 ostracods $\mathrm{cm}^{-2}$. The ostracods (mean length, $0.90 \mathrm{~mm}$ ) had been kept in culture and originated from the nearby Darß-Zingst coastal lagoon system. The cores were then placed in a water bath in an environmental chamber at $14^{\circ} \mathrm{C}$ and illuminated from above on a 18:6h light:dark cycle, with a mean light intensity of $222 \mu \mathrm{E}$ at the water surface. The experiment was begun on 8 July 1996, between 22:45 and 23:35 h, and ended 4 d later on 12 July 1996 between 14:00 and 16:20 $\mathrm{h}$. The mini-cores with and without ostracods were then extracted from the sediment, and sediment samples from the $0-5 \mathrm{~mm}$ and 5-10 $\mathrm{mm}$ depths were taken, fixed, and stained as described for the initial samples.

Ciliate abundance and diversity data were analyzed in pair-wise $t$-tests, which tested whether the mean difference in ciliate abundance between tubes with and without ostracods within each core was significantly different from zero. Because the test was performed on the differences within cores, the betweencore variance, which was considerable and could easily mask a large difference due to the experimental treatment, was eliminated from the statistical analysis. In order to restrict the number of statistical tests performed, and thereby the probability that a difference in treatments with and without ostracods would be falsely declared significant (a Type I error), ciliates were grouped into broad taxonomic or physiological groups for the statistical analysis. These groups were total ciliates, obligate anaerobes, hypotrichs, scuticociliates, and Blepharisma species. Nematodes were the only meiofauna group abundant enough for the data to be statistically analyzed. 


\section{RESULTS}

\section{Gradient establishment and sample staining}

Both centrifuge times and speeds were effective in establishing density gradients (Fig. 1). However, longer centrifuge times with either centrifuge speed produced a high-density pellet that could not be drawn into a pipette tip to be measured. There were no significant differences in the density gradients established or measured on different centrifuges or days, with the exception of gradients established on the Beckman centrifuge and measured immediately or $20 \mathrm{~d}$ later (Kolmogorov-Smirnov test, $\mathrm{p}=0.018$; all other comparisions, $\mathrm{p}>0.05$; Fig. 1). However, the gradients established using a centrifugation of $20000 \times g$ for $1 \mathrm{~h}$ did have a zone of higher density towards the bottom of the tube.

The density gradient was successful in separating ciliates from sediment. In 5 samples where the sediment pellet at the bottom of the centrifuge tubes was thoroughly examined after centrifugation, an average of 1.0 ciliate per sample was found, as well as 0.8 testate amoebae, 0.4 harpacticoid copepods, copepod nauplii or nematodes, and 0.2 ostracods. Because $85 \%$ of the filtered samples had a total of at least 40 ciliates, the loss of 1 ciliate $(\leq 2.5 \%)$ was deemed non-critical. None of the ciliates found were bound to sediment particles, suggesting no systematic error involving parti-

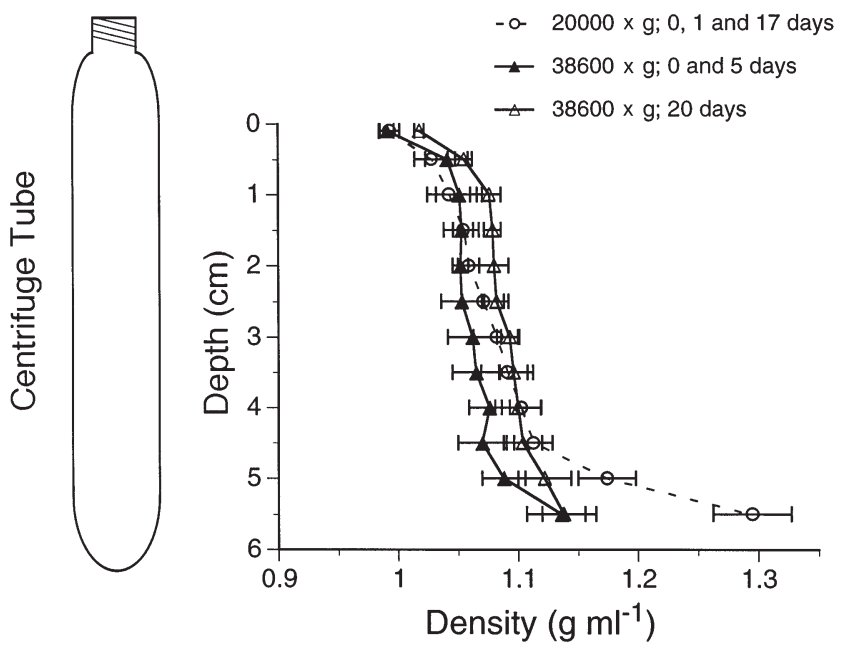

Fig. 1. Density gradients established in Percoll-water solutions. Depth is distance from the solution meniscus in the centrifuge tube, drawn to scale on the left. Data were grouped according to the significant differences found by Kolmogorov-Smirnov tests $(\alpha=0.05)$. (o) Gradients established at $20000 \times g$ measured 0,1 and $17 \mathrm{~d}$ afterwards. (ム) Gradients established at $38600 \times g$ and measured 0 or 5 d later. $(\Delta)$ Gradients established at $38600 \times g$ and measured $20 \mathrm{~d}$ later. The error bars are 1 standard deviation cle-bound ciliates. Of the meiofauna, only nematodes were abundant enough to count accurately, and the loss of, on average, 0.4 nematodes per sample was also thought acceptable. In 8 samples prepared by establishing a density gradient with centrifugation for $25 \mathrm{~min}$ at $38600 \times g$, and centrifuging the samples at $4300 \times g$ for $15 \mathrm{~min}$, there were no ciliates or meiofauna found in the sediment pellets.

After centrifugation, the ciliate samples could be successfully stained with the QPS procedure. It was critical that as little as possible of the sediment pellet (which usually had a loose consistency) be drawn out with the Pasture pipette and filtered. Not only did this make the protists easier to see, but if some of the sediment pellet was drawn into the pipette, then the application of agar often washed a considerable amount of the sample off the filter. Inspection with a dissecting microscope showed that this did not occur when only a minimal amount of sediment was on the filter. The only important modification to Skibbe's version of the QPS staining procedure was to lengthen the time the samples were bleached with potassium permanganate. The duration of this step was critical, with too short a period leaving the sample too dark to see the ciliature, and too long a period leaving the sample so bleached that little or nothing was subsequently stained. It was found that bleaching the sample for $6 \mathrm{~min}$ ( $7 \mathrm{~min}$ for the Wattenmeer sediment profiles), instead of the 5 min recommended by Skibbe for plankton samples, produced markedly better results (Fig. 2).

\section{Wattenmeer sediment}

Total ciliate abundance was high in the Wattenmeer sediment, especially in comparison to previously published values obtained using other methods (Kemp 1990, Epstein \& Gallagher 1992, Epstein 1995) and, to a lesser extent, to the Rassower Strom sediment used in the ostracod experiment (see below). In the layers between 0 and $10 \mathrm{~mm}$ depth (comparable to the ostracod experiment samples), ciliate abundance was between 1000 and 2500 cells ml $^{-1}$ (Fig. 3A). In the layers beneath $10 \mathrm{~mm}$, total ciliate abundance was considerably less, but did not drop beneath 180 ciliates $\mathrm{ml}^{-1}$. While there was considerable variance between the cores, and generally higher abundance in the second core, similar trends in both cores could be seen. There was reduced abundance with increased depth in both cores, but also in both, a peak in abundance at either the 4-6 or 6-8 $\mathrm{mm}$ depth. Ciliate biodiversity did not show any obvious trend with depth, and while both cores had identical diversity values (as measured by $H^{\prime}$ ) in the 0-2 mm layer, one core subsequently had consistently higher diversity than the other (Fig. 3B). Species diver- 


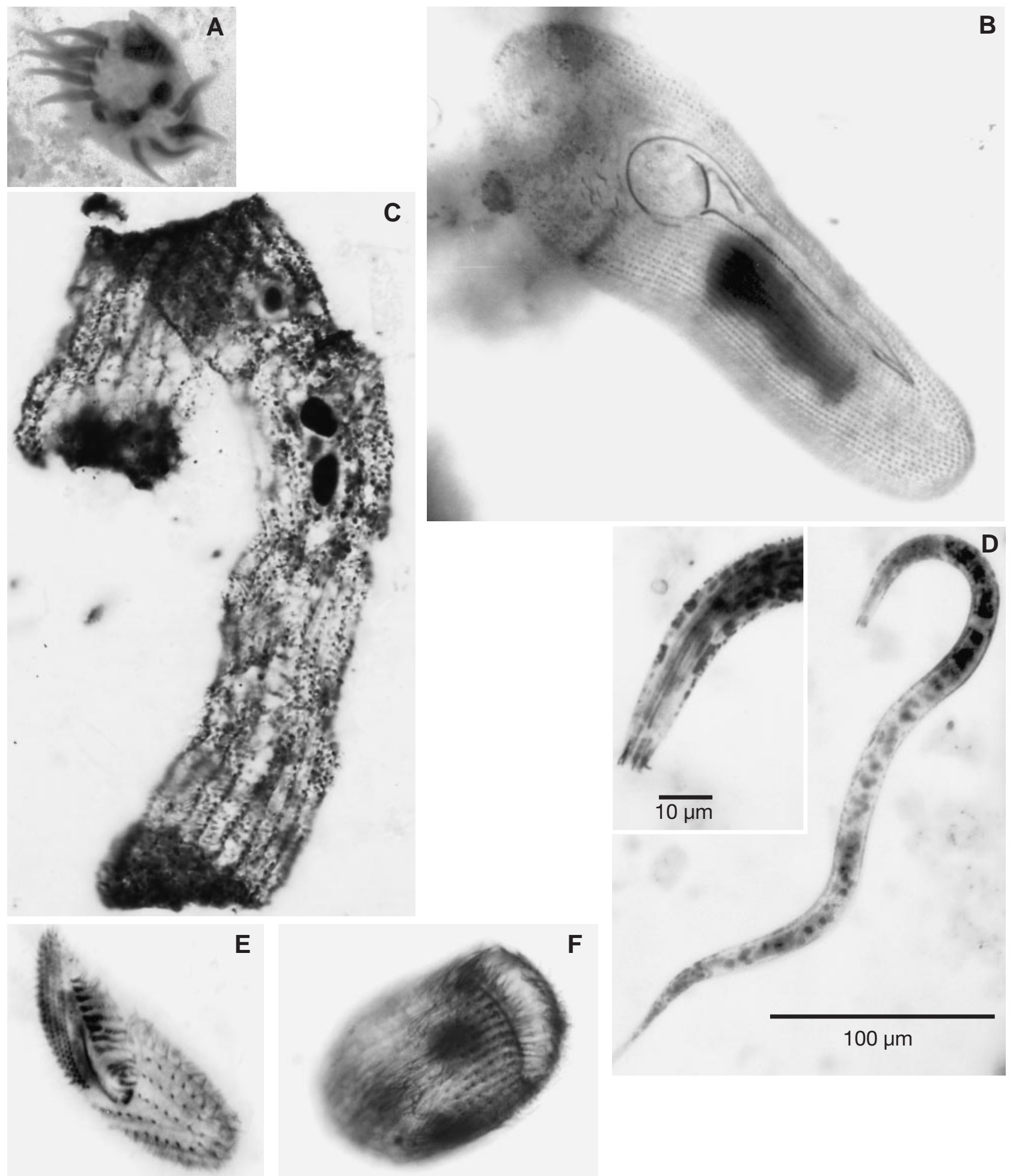

Fig. 2. Representative benthic ciliates stained with the density-gradient QPS methodology. (A) Aspidisca fusca, a hypotrich ciliate from the $0-5 \mathrm{~mm}$ layer of the ostracod experiment. (B) Pleuronema marinum, a scuticociliate from the $0-5 \mathrm{~mm}$ layer of the ostracod experiment. (C) Kentrophoros fasciolatum, from the Wattenmeer sediment. (D) An unidentified nematode (inset: the same nematode at higher magnification, showing the oral region). (E) Metopus setosus, an obligate anaerobic ciliate from the 5-10 mm layer of the ostracod experiment. (F) Sonderia sp., an obligate anaerobic ciliate from the 5-10 mm layer of the ostracod experiment. All ciliates and the nematode inset were photographed with a 100× objective. Scale bar for the ciliates and nematode inset is $10 \mu \mathrm{m}$. The whole nematode was photographed with a $40 \times$ objective; scale bar $=100 \mu \mathrm{m}$ 

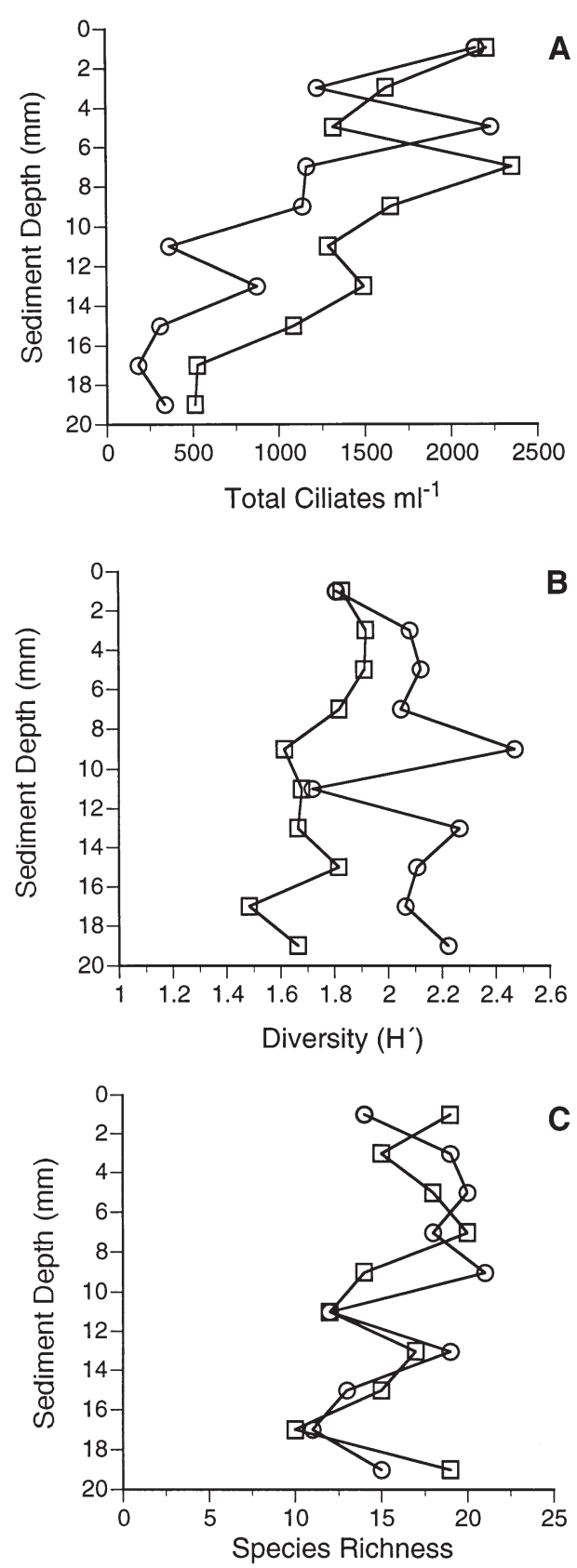

Fig. 3. Wattenmeer sediment profiles for 2 cores sampled at $2 \mathrm{~mm}$ intervals. (A) Total ciliate abundance in cells $\mathrm{ml}^{-1}$, (B) Shannon-Wiener diversity index $\left(H^{\prime}\right)$ and $(C)$ species richness (total number of species)

sity ranged between 1.48 and 2.47. Species richness (the number of species present) also did not show any obvious trend with increasing depth (Fig. 3C). There was a total of 41 species and morphotypes found in the 2 cores, but between 10 and 21 in any 2 mm layer. The peak in ciliate abundance between 4 and $8 \mathrm{~mm}$ and the subsequent decline was not mirrored in either the diversity or species richness data.
Table 1. Ostracod experiment. p-values from pairwise $t$-tests, testing the probability that there was no significant difference in abundance and diversity between tubes with and without ostracods. Pairwise tests calculate the difference between pairs of mini-cores (one with and one without ostracods) within each larger core, and then test whether the mean difference between pairs of mini-cores is significantly different from zero. This way the variance between the larger cores is discounted and cannot mask differences due to the addition of ostracods

\begin{tabular}{|lcc|}
\hline Group & \multicolumn{2}{c|}{ Depth (mm) } \\
& $0-5$ & $5-10$ \\
\hline Total ciliates & 0.006 & 0.631 \\
Hypotrichs & 0.023 & 0.470 \\
Scuticociliates & 0.060 & 0.575 \\
Anaerobic ciliates & 0.221 & 0.515 \\
Blepharisma sp. & 0.111 & 0.810 \\
Nematodes & 0.013 & 0.605 \\
Ciliate diversity & 0.671 & 0.011 \\
& & \\
\hline
\end{tabular}

The most consistently abundant group in the Wattenmeer cores were members of the family Cyclidiidae, species in the genera Cyclidium and Cristigera. These small scuticociliates had a maximum abundance of 720 cells $\mathrm{ml}^{-1}$ (in the $6-8 \mathrm{~mm}$ layer), and a mean

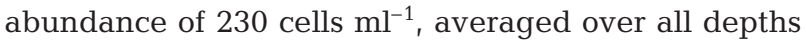
in the 2 cores (Fig. 4). The most abundant ciliate in any single layer was Mesodinium pulex, which had a maximum abundance of 850 cells $\mathrm{ml}^{-1}$ in the $0-2 \mathrm{~mm}$ layer of one core, or $40 \%$ of the total ciliate abundance in this layer and core. However, M. pulex was mostly confined to the surface layer, and did not make up more than $3 \%$ of the total abundance in any other layer. Also abundant in the surface layer was Chlamydodon mnemosyne, with a maximum abundance of 820 cells ml $\mathrm{m}^{-1}$. The most abundant ciliate in the deeper layers was Remanella spp., which had a maximum abundance of 540 cells $\mathrm{ml}^{-1}$ in the $12-14 \mathrm{~mm}$ layer (Fig. 4). Together, the 6 most abundant groups (Cyclidiidae, M. pulex, C. mnemosyne, Remanella spp., Euplotes spp. and Aspidisca sp.) made up 50\% of the total ciliate abundance. There was also a dominance of small-bodied groups. Four of the 6 most abundant groups (Cyclidiidae, M. pulex, Euplotes spp. and Aspidisca sp.) were smaller than $30 \mu \mathrm{m}$, and made up $33 \%$ of the total abundance, averaged over all depths and cores.

\section{Ostracod experiment}

Of the 200 ostracods $\left(43 \mathrm{~cm}^{-2}\right)$ placed in each tube, an average of $80 \%$ (mean \pm 1 standard deviation: 33.7 \pm 8.3 ostracods $\mathrm{cm}^{-2}$ ) were recovered at the end of the experiment. One-third of the ostracods $(11.4 \pm 6.0$ 

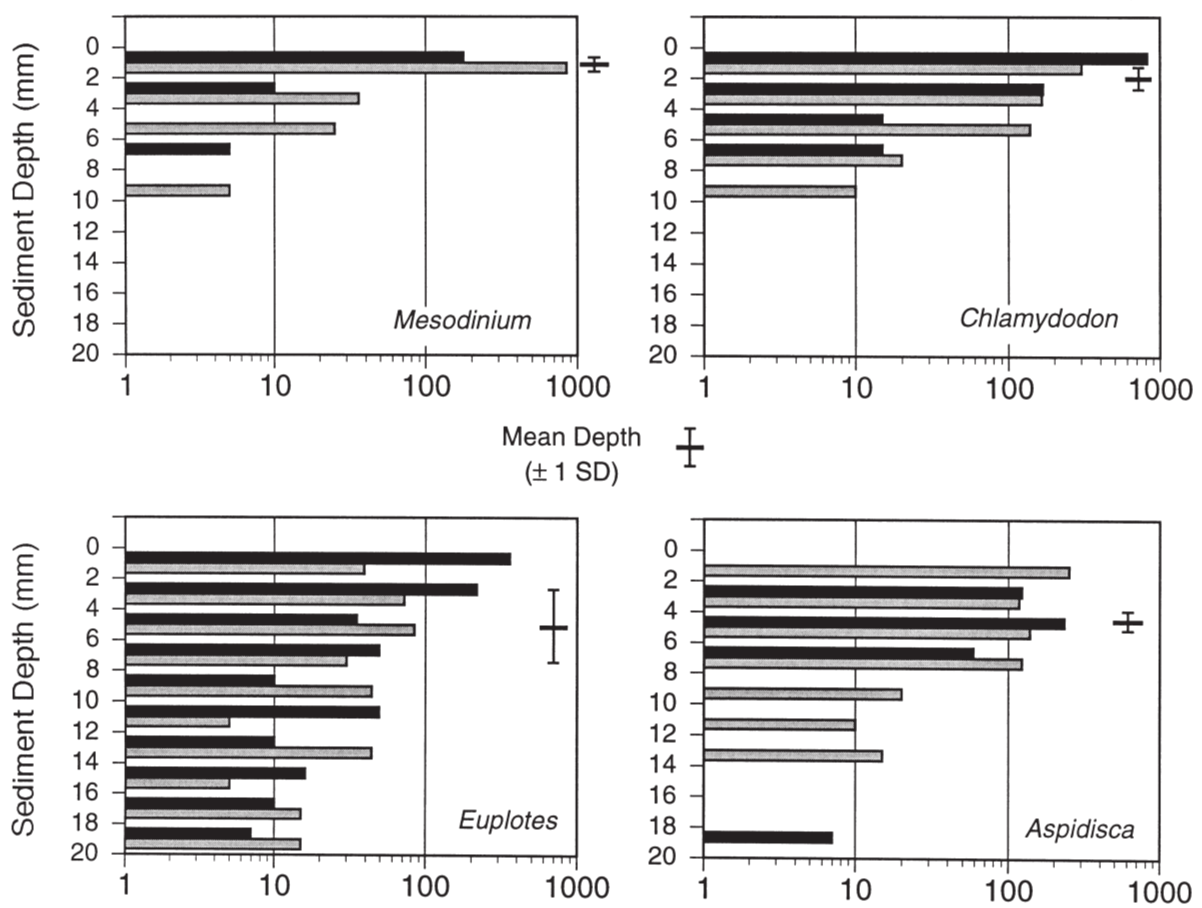
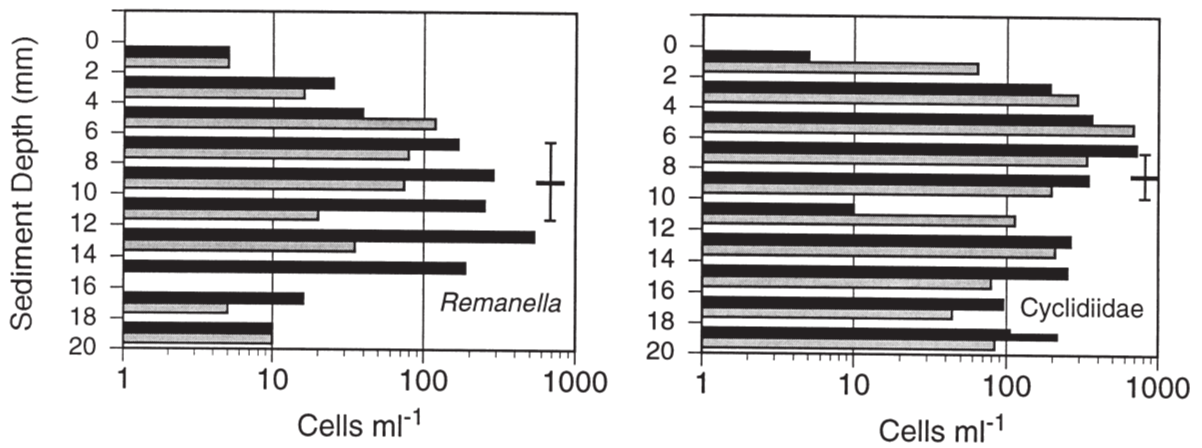

Fig. 4. Depth distributions for individual species and groups in the 2 Wattenmeer cores. Note the logscale for the abundance. Horizontal bars with vertical lines indicate the average of the mean depths for the 2 profiles, \pm 1 standard deviation ostracods $\mathrm{cm}^{-2}$ ) were found in the $0-5 \mathrm{~mm}$ sediment layer, while the rest $\left(22.3 \pm 3.7\right.$ ostracods $\left.\mathrm{cm}^{-2}\right)$ were in the 5-10 mm layer. In the tubes without added ostracods, the abundance of naturally occurring ostracods was low but followed this trend $(0.8 \pm 0.6$ ostracods $\mathrm{cm}^{-2}$ were found in the upper layer, and $2.2 \pm$ 0.6 ostracods $\mathrm{cm}^{-2}$ in the deeper layer).

In the 3 initial samples, a total of 36 ciliate species or morphotypes were found. There was moderately higher diversity in the upper layer (Fig. 5). A higher total number of species (42, Table 1) was found in the final samples, but there were a total of 12 cores ( 6 with, and 6 without ostracods) examined for the final samples, and only 3 cores for the initial samples. Initial, total ciliate abundance was 660 cells ml $^{-1}$ in the $0-5 \mathrm{~mm}$ layer, and 570 cells in the $5-10 \mathrm{~mm}$ layer. Of the 42 species and morphotypes found, 13 could be identified to species, and a further 26 to genus. Three species were obligate anaerobes (Metopus setosus, Parablepharisma bacteriophora, and Sonderia sp.). The total initial anaerobe abundance in the $0-5 \mathrm{~mm}$ layer was 160 cells $\mathrm{ml}^{-1}$, and 210 cells $\mathrm{ml}^{-1}$ in the 5-10 mm layer. There were 9 hypotrich species, with Aspidisca fusca and 2 Euplotes species being the most abundant (total initial hypotrich ciliates: $0-5 \mathrm{~mm}, 190$ cells $\mathrm{ml}^{-1}$; 5-10 mm, 84 cells $\mathrm{ml}^{-1}$ ). Three Blepharisma species were also found in the initial samples, with a total abundance of 35 cells $\mathrm{ml}^{-1}(0-5 \mathrm{~mm})$ and 19 cells $\mathrm{ml}^{-1}(5-10 \mathrm{~mm})$.

The addition of ostracods significantly affected ciliate diversity and abundance, but the effect on abundance was confined to the upper $5 \mathrm{~mm}$ layer, while the effect on diversity was only seen in the deeper layer. Total ciliate abundance was on average $~ 50 \%$ less in treatments with ostracods in the $0-5 \mathrm{~mm}$ layer, but not significantly different in the 5-10 mm layer (Fig. 5, Table 1). Among the main ciliate groups, only the 

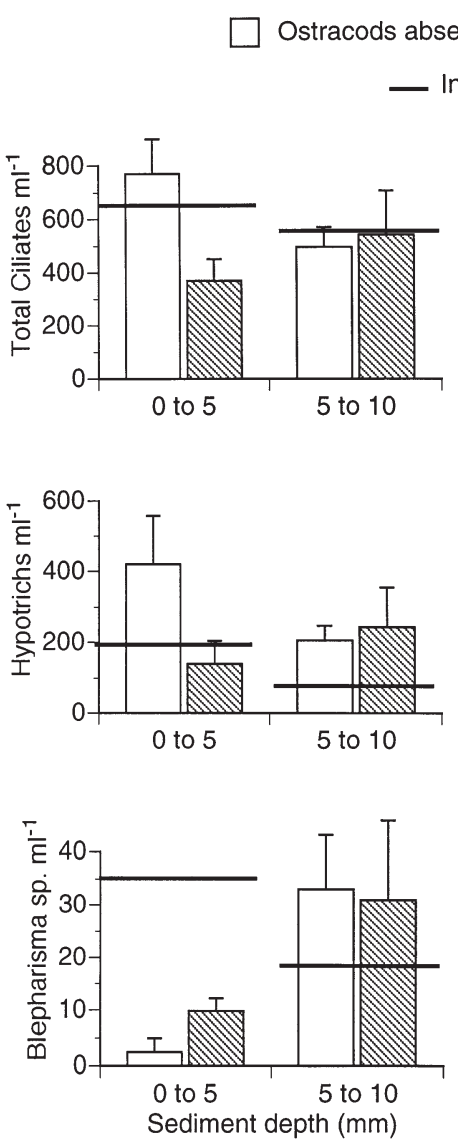
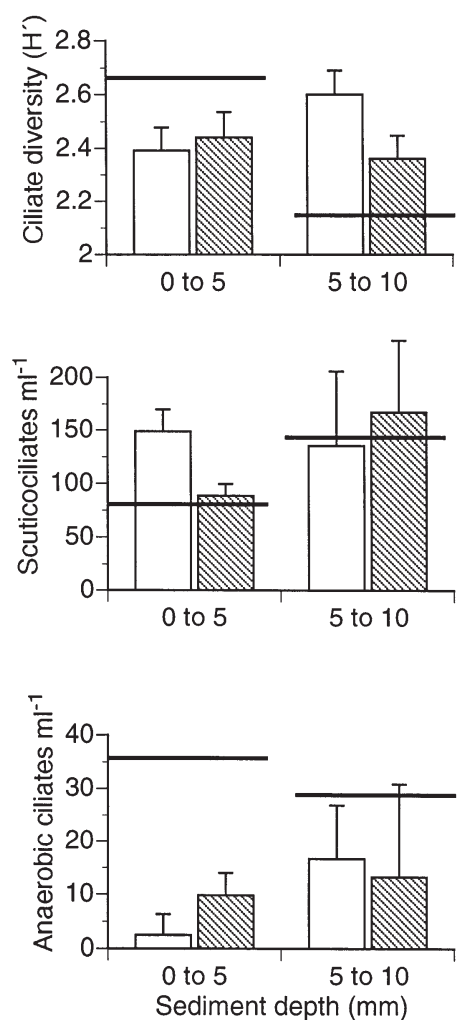

Fig. 5. Initial and final ciliate abundance and diversity in the $0-5$ and 5-10 mm depths of the ostracod experiment. Horizontal lines represent the initial abundance or diversity; open bars are the final values in the absence of additional ostracods, and hatched bars are the final values in the presence of additional ostracods. Error bars represent 1 standard error. Note the difference in the scales used in the $y$-axes (ind. $\mathrm{ml}^{-1}$ ). Diversity is measured by the Shannon-Wiener diversity index $\left(H^{\prime}\right)$

total ciliate abundance, but in the presence of ostracods, their contribution increased to $\sim 40 \%$ of the total abundance. In addition, 7 rare species (together $\leq 1.2 \%$ total abundance) were found only when ostracods were absent.

Ciliate diversity in the 5-10 $\mathrm{mm}$ layer was considerably higher at the end of the experiment in both ostracod present and absent treatments than in the initial samples. This was due to the dominance of Kentrophoros fasciolatum in the initial samples, in which it comprised almost $35 \%$ of the total ciliate abundance. In samples at the end of the experiment, $K$. fasciolatum comprised less than $6 \%$ of the total abundance, a proportion that was unaffected by the presence or absence of ostracods.

Total nematode abundance increased in the presence of ostracods in the 0-5 mm layer, but not the 5-10 mm layer (Table 1). In addition, there was a sizeable increase in nematode abundance in both treatments in the 5-10 mm layer from the beginning to end of the experiment.

\section{DISCUSSION}

The combination of the QPS technique with non-linear density-gradient centrifugation is at the moment the most effective method of obtaining quantitative, species-specific information about benthic ciliates. Unlike Uhlig's method, we ob-

abundance of the hypotrichs and the scuticociliates was depressed by addition of ostracods, and only in the 0-5 mm depth. There were no effects of ostracods on any of the ciliate groups in the 5-10 mm layer $(\mathrm{p}>0.05$, Fig. 5). However, diversity significantly declined in the 5-10 mm layer in the presence of ostracods, with fewer species dominating the total ciliate abundance ( $\mathrm{p}=$ 0.011, Fig. 5). Without ostracods, species richness was greater (35 species in total, while there were 29 species with ostracods present), and the distribution of abundance between species more even. In contrast, there was no change in ciliate diversity in the $0-5 \mathrm{~mm}$ layer $(p=0.67)$, despite the significant change in total abundance. The decrease in diversity in the 5-10 $\mathrm{mm}$ depth was largely due to the increase in relative abundance of the already abundant Uronema sp., Blepharisma sp. 2, Pleuronema marinum and Holosticha fasciola. Without ostracods, these 4 species made up $\sim 30 \%$ of the tained a quantitative estimate of ciliate abundance, and unlike live-counting, we could work with a large number of samples and produce a permanent record. Our method effectively separates ciliates from sediment, stains the cells well enough that many morphotypes can be identified to at least genus, and allows counts to be made with enough individuals that hypotheses about the control of abundance and biodiversity can be tested. In the ostracod experiment, we distinguished 42 species or morphotypes, while in the Wattenmeer profiles we found a total of 41 groups or species, with up to 21 groups or species in any one $2 \mathrm{~mm}$ layer. We could also slice the sediment finely enough (into either $5 \mathrm{~mm}$ [ostracod experiment] or $2 \mathrm{~mm}$ [Wattenmeer sediment] sections) to obtain fine scale information about ciliate depth distributions. Moreover, the method produces a permanent record that can be checked months or years later. 
Meiofauna could also be separated from sediment with the non-linear density gradient centrifugation, and nematodes, harpacticoid copepods and copepod nauplii could also be well stained with the QPS technique. However, in our samples only nematodes were abundant enough to be counted reliably. While we did not attempt to further identify nematodes, they were stained well enough that this may be possible (Fig. 2). The extraction efficiency of Percoll declines when the volume to volume ratio of diluted Percoll to sample drops beneath 4:1 (Schwinghamer 1981, Starink et al. 1994), meaning that in a $10 \mathrm{ml}$ centrifuge tube, not more than $2 \mathrm{ml}$ of the washed sample can be used. In the ostracod experiment, the initial $2.33 \mathrm{ml}$ sediment sample was diluted down to $25 \mathrm{ml}$ by washes to remove some of the sediment prior to centrifugation. We then centrifuged $1.5 \mathrm{ml}$ of this sample, equivalent to $0.14 \mathrm{ml}$ of the original sample. As a result, ciliates or meiofauna need to be abundant before they can be counted precisely. Almost all our samples had a ciliate abundance in excess of 200 cells $\mathrm{ml}^{-1}$, with maximum abundance greater than 2300 cells $\mathrm{ml}^{-1}$, providing sufficient material for reliable counts. However, when ciliate abundance is lower, or it is critical to count and identify the rarest species, eliminating the preliminary washes should be considered. In finer sediment, as with the Wattenmeer samples, washes can be reduced in number or not performed at all and an acceptable initial separation of sediment from ciliates or meiofauna will still be obtained. In very sandy sediment, on the other hand, it may be possible to simply wash the sample with the rinses described in the 'Material and methods', and not perform with the non-linear centrifugation. This was successfully done to identify a Euplotes species in an artificial sand sediment (S.W. pers. obs.).

The high ciliate abundance found in the Wattenmeer sediment may mean that the conclusion that ciliates are unlikely to exert significant grazing pressure on benthic bacteria (Kemp 1988, 1990, Epstein \& Shiaris 1992) needs to be re-evaluated. 1500 ciliates $\mathrm{ml}^{-1}$ in sediment with a water content of $31 \%$ need only to filter $4.3 \mathrm{nl}$ ciliate $\mathrm{C}^{-1} \mathrm{~h}^{-1}$ to remove $50 \%$ of all bacteria each day, a clearance rate well below that reported for pelagic ciliates (e.g. Sherr \& Sherr 1987, Šmek et al. 1996). It is clearly dangerous to make comparisons between grazing on benthic and pelagic bacteria, with much depending on how far the pelagic rates are beneath the maximum potential ingestion rate, and how available the benthic bacteria are to ciliates. Nevertheless, if the lower ciliate abundance previously reported (e.g. Kemp 1990, Epstein \& Gallagher 1992, Epstein 1995) was due to methodological problems, then benthic ciliates may indeed be more important benthic bacterial consumers than previously thought.
In addition, the strong qualitative and quantitative effects of ciliates on benthic diatom communities that have been observed (changing community structure and grazing up to $19 \%$ of daily benthic diatom production) may be a common phenomenon (McCormick 1991, Balczon \& Pratt 1996).

In the Wattenmeer sediment, our method allowed us to distinguish differences in the fine-scale depth distributions of the different groups or species. Mesodinium and Chlamydodon were both confined to the upper few millimeters of the sediment, with a mean depth distribution of 1.3 and $2.1 \mathrm{~mm}$, respectively (Fig. 4). At least a few Remanella cells could be found at all depths, but the majority of the population could be found relatively deep in the sediment, at an average depth of $9.5 \mathrm{~mm}$. Several of the species or groups abundant in the Wattenmeer profiles were found much deeper in the sediment than would be expected from their known oxygen preferences. Maximal oxygen penetration in these sediments is typically about $4 \mathrm{~mm}$ (Berninger \& Epstein 1995, Forster et al. 1996) However, the Cyclidiidae and Euplotes sp. could be found at all depths, and their mean depth distributions were at 8.6 and $5.4 \mathrm{~mm}$, respectively (Fig. 4). Aspidisca sp. had a shallower mean depth distribution $(4.4 \mathrm{~mm})$, but a few individuals were found as deep as $20 \mathrm{~mm}$. Berninger \& Epstein (1995) reported the same phenomenon in their depth profiles, finding epibenthic ciliates beneath the maximum oxygen penetration depth. Microaerophilic ciliates have been shown in the laboratory to confine themselves to a narrow range of oxygen concentrations (Fenchel et al. 1989, Fenchel \& Bernard 1996), and ciliate communities are known to change their vertical position in the sediment with changes in oxygen penetration (Berninger \& Epstein 1995). Nevertheless, both our work and that of Berninger \& Epstein would suggest that while ciliates can orient themselves in a oxygen gradient, they are often found outside their preferred oxyen concentration. There is also evidence that the depth distribution of algal prey overrides the oxygen preferences of an Euplotes species (U.G.B. unpubl. data). The presence of ostracods did not drive the ciliates any deeper into the sediment (Fig. 5), suggesting that predator avoidance is not the reason for ciliates commonly described as aerobic being found in anoxic sediment. The 2 groups suppressed by ostracods (hypotrichs and scuticociliates) are normally thought to be epibenthic, but were found in both the $0-5$ and $5-10 \mathrm{~mm}$ layers. It is unlikely that extruding the sediment from the minicores and slicing them substantially disturbed the ciliate distribution. Despite any potential disturbance of the sediment, it was still possible to discern obvious differences in the depth distributions of the ciliates, particularly in the Wattenmeer sediments. Mesodi- 
nium, for example, had a mean depth of $1.3 \mathrm{~mm}$, while the center of Euplotes' distribution was at $5.4 \mathrm{~mm}$. Thus, disturbance through extruding the cores seems unlikely to be the explanation for finding aerobic ciliates in anoxic sediment.

The ostracod experiment demonstrated that despite the heterogeneity of benthic ciliate distributions, the method developed here is accurate enough to use in manipulative experiments, with both highly significant and non-significant effects. Use of a pair-wise $t$-test and a relatively large number of replicates (6) was sufficient to overcome the high between-replicate variance. Over the course of the experiment, there was a general movement of Blepharisma species to the deeper layer, and a loss of anaerobic ciliates in comparison to the initial values, but overall most effects were attributable to the experimental manipulation (Fig. 5). Ostracods had a direct impact on ciliates, reducing their abundance, but the effect was group specific and confined to the upper $5 \mathrm{~mm}$ of the sediment. The reduction in ciliate abundance in the presence of ostracods did not result in an increase in ciliate diversity in the 0-5 mm layer, making it unlikely that ostracods were acting as a 'keystone predator' (sensu Paine 1966). Increasing diversity is known to occur when a keystone predator suppresses a species or group that would otherwise dominate the biomass of a community. Instead, the results are consistent with a ciliate community that was already under predation pressure.

While the effects of ostracods on ciliate abundance were confined to the upper $5 \mathrm{~mm}$, the majority of ostracods were found in the deeper layer. There was a negative effect of ostracods on ciliate diversity and species richness in this layer, suggesting that the ostracods were not entirely inactive. The main effect of ostracods in the deeper layer may have been through bioturbation, allowing deeper oxygen penetration. Species such as Pleuronema and Uronema, which are often planktonic and aerobic, increased in abundance in this layer in the presence of ostracods. There was, however, no decline in the abundance of anaerobic species in the presence of ostracods, suggesting that there is no single explanation that can account for the results in the $0-5 \mathrm{~mm}$ layer. The positive response of nematode abundance to the presence of ostracods also suggests that indirect effects of ostracods were important. Possible explanations include bioturbation by ostracods releasing nutrients that could then be used by algae and bacteria, which are in turn grazed by nematodes, or processing of sediment and detritus by ostracods, making them more available to nematodes. However, testing these hypotheses was beyond the scope of this study.

The ostracod density we used (end abundance, 34 ostracods $\mathrm{cm}^{-2}$ ) was high, but not unrealistically so. A survey of meiofauna abundance in the nearby Greifswalder Bodden showed that in a $40 \times 40 \mathrm{~cm}$ quadrate, $8.7 \%$ of the area had an ostracod abundance $>20$ ostracods $\mathrm{cm}^{-2}$, and in $1.5 \%$ of the quadrate, there was an ostracod abundance in excess of 25 ostracods $\mathrm{cm}^{-2}$ (Arlt 1973). Thus, while the magnitude of the ostracod effects we saw in the experiment may be greater than what normally occurs in the field, we would expect that our results are at least qualitatively representative.

While we were able to successfully stain and count ciliates using the method developed here, the method does have its limitations. Not all sediment is separated equally well from the ciliates. Anecdotal evidence would suggest that extremely fine sediment is not entirely removed from ciliates, and much clearer results are obtained from sandy sediment. Organic sediment appears to compete with ciliates for the permanganate, resulting in masking both through the physical presence of the sediment over the ciliate cells, and by insufficient bleaching of the ciliates. Lengthening the permanganate step ensures that the ciliates are sufficiently bleached, and lightens the color of the organic component of the sediment. However, if too much sediment is present on the filter, there is still the problem of the agar washing cells off the filter before the agar has hardened. Therefore, a test preparation must be made in order to establish the appropriate sample volume and staining times. A normal staining sequence, from centrifuging the sample to finally embedding the filter on a slide, can be expected to take approximately $4 \mathrm{~h}$, with a practical maximum of approximately 10 samples per staining run. Our experience is that the time required to count the resulting preparations is approximately 1 to $2 \mathrm{~h}$ per filter, once the main ciliate groups have been identified. As a result, counting benthic ciliate samples is a rather labor-intensive enterprise.

Another consideration when using the method is that, as previously pointed out by various authors (Choi \& Stoecker 1989, Jerome et al. 1993, Pfister et al. 1999), both fixation and QPS staining results in species-specific shrinkage of ciliates. As a result, caution needs to be used when calculating biovolumes or biomasses. Shrinkage can also cause distortion in ciliate body shape, making identification difficult. The fixative we used, glutaraldehyde, is not commonly used for ciliates, and may lead to the selective loss of some benthic species (Anik Güber pers. comm.). The problem of Bouin's, and presumably other acidic fixatives, which cause Percoll to gel, can be circumvented if the time between centrifuging the samples and collecting them on filters is kept to under $30 \mathrm{~min}$. Centrifugation in a Percoll solution itself does not apparently harm the fixed cells. While we did not attempt to quantify any 
loss due to centrifugation, Percoll has been reported as being useful for centrifuging live ciliates, algae and meiofauna (Price et al. 1978, Schwinghamer 1981, Alongi 1986). We did find that the centrifugation times and speeds we used were successful in forming the sediment into a pellet that did not contain any appreciable numbers of ciliates or, with the exception of ostracods, meiofauna. We did not test for the efficiency of the combined centrifugation-QPS method. However, recent evidence suggests that, at least for pelagic samples, the QPS method does not result in lower ciliate abundance than live counting (Pfister et al. 1999). In addition, Percoll gradients have been shown to recover up to $100 \%$ of flagellates from sandy sediments, and up to $94 \%$ of flagellates from finer sediments (Starink et al. 1994). Actual recovery percentages will undoubtedly vary with sediment type and the ciliate community present, but given the relatively high total abundance we obtained in both the Wattenmeer and ostracod experiment cores, we believe that losses due to the method used are relatively low.

Despite the shortcomings noted above, the methodology outlined and applied in this paper appears to give, at the moment, the best combination of taxonomic resolution and counting precision. This combination is probably the minimum necessary to quantitatively answer relevant ecological questions, and can hopefully in the future be improved upon. Dini \& Nyberg (1999) have recently demonstrated differences in feeding efficiencies not only between but also within Euplotes species, suggesting that many ecological questions involving benthic ciliates will require the best possible taxonomic resolution. Basic questions of trophic interactions, such as whether ciliates are predators, competitors or prey to other groups, will also almost certainly require species-level abundances. In this paper we have shown that we can use our technique to investigate predator-prey interactions at both a broad and fine taxonomic scale. In addition, we were able to demonstrate distributions of benthic ciliates at both a fine spatial and taxonomic scale. Clearly this was only a first step, but we hope that the methodology and results presented will further the study of benthic ciliates.

Acknowledgements. We thank Günter Arlt for supplying the ostracods, and colleagues in the Institute for Ecology, Hiddensee, and Stella Eix (Max Planck Institut, Bremen) for obtaining the sediment cores used in the experiments. We also thank 4 anonymous reviewers for their comments on an earlier version of the manuscript. This work was supported by the German Bundesministerium für Bildung und Forschung through the multidisciplinary project 'Ökobod: Ökosystem Boddengewässer-Organismen und Stoffhaushalt' and by the Max Planck Society.

\section{LITERATURE CITED}

Alongi DM (1986) Quantitative estimates of benthic protozoa in tropical marine systems using silica gel: a comparison of methods. Estuar Coast Shelf Sci 23:443-450

Arlt G (1973) Vertical and horizontal microdistribution of the meiofauna in the Greifswalder Bodden. Oikos (Suppl) 15: 105-111

Balczon JM, Pratt JR (1996) The functional response of two benthic algivorous ciliated protozoa with differing feeding strategies. Microb Ecol 31:209-224

Berninger UG, Epstein SS (1995) Vertical distribution of benthic ciliates in response to the oxygen concentration in an intertidal North Sea sediment. Aquat Microb Ecol 9: 229-236

Berninger UG, Huettel M (1997) Impact of flow on oxygen dynamics in photosynthetically active sediments. Aquat Microb Ecol 12:291-302

Brown JH (1984) On the relationship between abundance and distribution of species. Am Nat 124:255-279

Carey PG (1992) Marine interstitial ciliates: an illustrated key. Chapman and Hall, London

Choi JW, Stoecker DK (1989) Effects of fixation on cell volume of marine planktonic ciliates. Appl Environ Microbiol 55: 1761-1765

Dini F, Nyberg D (1999) Growth rates of marine ciliates on diverse organisms reveal ecological specializations within morphospecies. Microb Ecol 37:13-22

Epstein SS (1995) Simultaneous enumeration of protozoa and micrometazoa from marine sandy sediments. Aquat Microb Ecol 9:219-227

Epstein SS (1997) Microbial food webs in marine sediments. I. Trophic interactions and grazing rates in two tidal flat communities. Microb Ecol 34:188-198

Epstein SS, Gallagher ED (1992) Evidence for facilitation and inhibition of ciliate population growth by meiofauna and macrofauna on a temperate zone sandflat. J Exp Mar Biol Ecol 155:27-39

Epstein SS, Shiaris MP (1992) Rates of microbenthic and meiobenthic bacterivory in a temperature muddy flat community. Appl Environ Microbiol 58:2426-2431

Fenchel T (1969) The ecology of marine microbenthos. IV. Structure and function of the benthic ecosystem, its chemical and physical factors and the microfauna communities with special reference to the ciliated protozoa. Ophelia 6: $1-186$

Fenchel T, Bernard C (1996) Behavioural responses in oxygen gradients of ciliates from microbial mats. Eur J Protistol 32: 55-63

Fenchel T, Finlay BJ, Gianni A (1989) Microaerophily in ciliates: responses of an Euplotes species (Hypotrichida) to oxygen tension. Arch Protistenkd 137:317-330

Fenchel T, Esteban GF, Finlay BJ (1997) Local versus global diversity of microorganisms: cryptic diversity of ciliated protozoa. Oikos 80:220-225

Finlay BJ, Esteban GF (1998) Freshwater protozoa: biodiversity and ecological function. Biodivers Conserv 7 : 1163-1186

Finlay BJ, Laybourn J, Strachan I (1979) A technique for the enumeration of benthic ciliated protozoa. Oecologia 39: 375-377

Finlay BJ, Corliss JO, Esteban G, Fenchel T (1996) Biodiversity at the microbial level: the number of free-living ciliates in the biosphere. Q Rev Biol 71:221-237

Forster S, Huettel M, Ziebis W (1996) Impact of boundary layer flow velocity on oxygen utilization in coastal sediments. Mar Ecol Prog Ser 143:173-185 
Gasol JM (1993) Benthic flagellates and ciliates in fine freshwater sediments: calibration of a live counting procedure and estimation of their abundance. Microb Ecol 25: 247-262

Goulder R (1971) The effects of saprobic conditions on some ciliated Protozoa in the benthos and hypolimnion of a eutrophic pond. Freshw Biol 1:307-318

Hairston NG (1969) On the relative abundance of species. Ecology 50:1091-1094

Jerome CA, Montagnes JS, Taylor FJR (1993) The effect of the quantitative protargol stain and Lugol's and Bouin's fixatives of cell size: a more accurate estimate of ciliate species biomass. J Eukaryot Microbiol 40:254-259

Jørgensen BB, Revsbech NP ( 1985) Diffusive boundary layers and the oxygen uptake of sediments and detritus. Limnol Oceanogr 30:111-122

Kahl A (1930-1935) Urtiere oder Protozoa: I: Wimpertiere oder Ciliata (Infusoria), eine Bearbeitung der freilebenden und ectocomensalen Infusorien der Erde, unter Ausschluß der marinen Tintinnidae. In: Dahl F (ed) Die Tierwelt Deutschlands. G. Fischer, Jena, p 1-886

Kemp PF (1988) Bacterivory by benthic ciliates: significance as a carbon source and impact on sediment bacteria. Mar Ecol Prog Ser 49:63-71

Kemp PF (1990) The fate of benthic bacterial production. Rev Aquat Sci 2:109-124

Kühl M, Lassen C, Jørgensen BB (1994) Optical properties of microbial mats: light measurements with fiber-optic microprobes. In: Stal LJ, Caumette P (eds) Microbial mats. Springer-Verlag, Berlin, p 149-166

Lucchesi P, Santangelo G (1997) The interstitial ciliate microcommunity of a Mediterranean sandy shore under differing hydrodynamic disturbances. Ital J Zool 64:253-259

Lynn DJ (1992) Protargol staining. In: Lee JJ, Soldo AT (eds) Protocols in protozoology. Society of Protozoologists, Lawrence, p C4.1-C4.8

MacArthur RH (1957) On the relative abundance of bird species. Proc Natl Acad Sci US 43:293-295

MacArthur RH, Wilson EO (1967) The theory of island biogeography. Princeton University Press, Princeton

McCormick PV (1991) Lotic protistan herbivore selectivity

Editorial responsibility: John Dolan,

Edgewater, Maryland, USA and its potential impact on benthic algal assemblages. $\mathrm{J} \mathrm{N}$ Am Benthol Soc 10:238-250

Montagnes DJS, Lynn DH (1987) A quantitative protargol stain (qps) for ciliates: method description and test of its quantitative nature. Mar Microb Food Webs 2:83-93

Paine RT (1966) Food web complexity and species diversity. Am Nat 100:65-75

Pfister G, Sonntag B, Posch T (1999) Comparison of a direct live count and an improved quantitative protargol stain (QPS) in determining abundance and cell volumes of pelagic freshwater protozoa. Aquat Microb Ecol 18: 95-103

Price CA, Reardon EM, Guillard RRL (1978) Collection of dinoflagellates and other marine microalgae by centrifugation in density gradients of a modified silica gel. Limnol Oceanogr 23:548-553

Schwinghamer P (1981) Extraction of living meiofauna from marine sediments by centrifugation in a silica sol-sorbitol mixture. Can J Fish Aquat Sci 38:476-478

Sherr EB, Sherr BF (1987) High rates of consumption of bacteria by pelagic ciliates. Nature 325:710-711

Šimek K, Macek M, Pernthaler J, Straskrabová V, Psenner R (1996) Can freshwater planktonic ciliates survive on a diet of picoplankton? J Plankton Res 18:597-613

Skibbe O (1994) An improved quantitative protargol stain for ciliates and other planktonic protists. Arch Hydrobiol 130: 339-347

Small, EB, Lynn DH (1985) Phylum Ciliophora. In: Lee JJ, Hunter SH, Bovee EC (eds) An illustrated guide to the protozoa. Society of Protozoologists, Lawrence, p 393-575

Starink M, Bär-Gilissen MJ, Bak RPM, Cappenberg TE (1994) Quantitative centrifugation to extract benthic protozoa from freshwater sediments. Appl Environ Microbiol 60: $167-173$

Tilman D (1996) Biodiversity: population versus ecosystem stability. Ecology 77:350-363

Tilman D, Downing JA (1994) Biodiversity and stability in grasslands. Nature 367:363-365

Uhlig G (1964) Eine einfache Methode zur Extraktion der vagilen mesopsammalen Mikrofauna. Helgol Wiss Meeresunters 11:178-185

Submitted: February 7, 2000; Accepted: May 15, 2000

Proofs received from author(s): June 30, 2000 